\title{
Qualitative Characterization of Gum Guar (Cymopsis tetragonoloba L.) Genotypes
}

\author{
Niranjana Kumara $B^{1}$, Gangaprasad $S^{2}$ and Sridhara $S^{3}$
}

\begin{abstract}
Eighty five guar (Cymopsis tetragonoloba L.) genotypes were collected from NBPGR, RRS, Jodhpur, Rajasthan and conducted field experiment in University of Agricultural and Horticultural Sciences, Shivamogga, Karnataka, India in the year 2014 (Kharif). The experiment was laid in RCBD and its composed of seven qualitative characters viz., Stem type, Growth habit, Leaf surface, Leaf margin, Leaf type flower color and seed color. With respect to stem type the most of the genotypes (75) were single stem and rest 9 genotypes were with branches, about 76 genotypes were bushy type remaining 7 were erect type, regarding leaf surface trait most of them(74) are glabrous and other 10 were pubescent, in leaf margin character 73 genotypes were smooth margin and rest 11 were serrated margin, with respect to leaf type trait narrow leaf type were found in more genotypes(72) and remaining 12 genotypes were recorded broad leaves, about 74 genotypes were found with purple color flower and 10 genotypes were with white color flowers and the seed coat color trait the 22 genotypes were grey green and others are various colors like black and grey brown group. Promising genotypes were selected based on the non branched and growth habit along with the leaf surface characters can be utilized in future improvement through breeding programme.
\end{abstract}

Keywords - Genotypes, Leaf surface, Guar, NBPGR.

\section{INTRODUCTION}

$\mathrm{C}$ LUSTER bean originated from Indian subcontinent of asia and is grown over arid and semiarid regions of the world (Purseglove, 1981). Its commonly known as guar is one of the underutilized legume, its exploited versatile and multipurpose legume vegetables. Its cultivated for feed, fodder and manure. Although cluster bean is a minor crop but due to its better and finer guar gum qualities its considered as an important cash crop for industrial gum production(Hymowitz and motlock (1963); Pathak and Singh (2010)). In agriculture guar gum is utilized as water retainer, soil aggregate and anticrusting agent. Guar gum has also greater utility in pollution control and acts as absorbent in waste water treatment in textile industry as flocculating and exchanging agent (Mahalonobis, 1936).

Seed of guar has rather large endosperm unlike most of other legumes and contains gene which is galactomannan polysaccharide, galactomannan is a natural thickner that is

\footnotetext{
${ }^{1}$ Department of Forest Biology and Tree Improvement, College of Forestry,Ponnampet

${ }^{2}$ Department of Genetics and Plant Breeding, College of Agriculture

${ }^{3}$ Department of Agronomy, College of Agriculture,

University of Agricultural and Horticultural Sciences, Shivamogga, Karnataka, India.
}

water soluble at low temperature. Guar gum has emerged as the most important agrochemical, which is non-toxic, ecofriendly and generally recognized as safe by FDA.

Despite the importance of this crop only limited breeding work has been done and very little attention has been given for its genetic improvement in the past in order to enhance the productivity levels of cluster bean. Information on the nature and magnitude of genetic diversity present in the genotypes is a pre-requisite. An attempt to made the study of qualitative traits which influencing on the quality of gum content and yield of gum guar..

\section{MATERIALS AND METHODS}

Eighty four genotypes of guar were obtained from different regions of the country which represented different geographic diversity. These genotypes constituted as base materials for this study. Environment of the farm is geographically located at of $13^{\circ} 55^{\prime} 47.74^{\prime \prime} \mathrm{N}$ latitude and $75^{\circ} 34^{\prime} 5.16^{\prime \prime} \mathrm{E}$ longitude at an elevation of $640 \mathrm{~m}$ above mean sea level. Annual average rainfall is $1813.9 \mathrm{~mm}$. The experiment was laid out in Randomized Complete Block Design at each season during summer 2014 and Kharif 2014. Each genotype was sown in a five rows of one meter length in each replication with a spacing of $30 \times 10 \mathrm{~cm}$ composed of three replications. Followed the normal recommended package of practices to maintain the crop stand. A total of seven qualitative characters viz., seed color, flower color, leaf surface, stem type, leaf margin, growth habit and leaf type were studied and the scores were assigned as per the guide lines by USDA, ARS, National Genetic Resources Program, Germplasm Resources Information Network(GRIN).Stem type: Main stem of the plant was observed for presence or absence of branches and number of branches were recorded (fig.1).Growth habit: Crop canopy stand behavior was considered as growth habit, the growth was observed for bushy and erect canopy pattern. Leaf surface:Small white hooked hairs on the surface of the leaf considered as pubescent and leaf surface without such hairs was glabrous and same pattern of hairiness also found in stem also and entire plant was observed for hairiness. Leaf margin: The margin of leaf was observed for the presence of smooth and serrated pattern. Leaf type: The size and shape of the leaf was recorded for broad and narrow shape. Flower color: Color of the flower was recorded by using Royal Horticultural Society (RHS) color chart. Seed color: Seed color was categorized based on Royal Horticulture Society (RHS) color chart, Five grades of color was observed namely grey group, grey- brown group, grayed-green group, grayed- 
yellow group and brown group.

\section{RESULTS AND DISCUSSION}

Observations on seven qualitative traits namely stem type, growth habit, leaf surface, leaf margin, leaf type, flower colour and seed colour were recorded for all the 85 genotypes and score was given for analysis (Table 2 and Table 3). Stem type:Maximum number of genotypes (75) (single stem) were observed with non branched stem type, however, nine genotypes namely IC-421817, IC-370478, IC-402296, IC415106, IC-514123, IC-415145, IC-415146, IC-415161 and IC-420373 were branched stem type (Table 2). Growth habit: Two groups namely bushy and erect were observed. Bushy type was found in 76 genotypes and eight genotypes were erect in nature (Table 2). Leaf surface: Maximum number of genotypes (74) was found with glabrous leaf surface and ten genotypes namely IC-311440, IC-323992, IC-325806, IC415108, IC-415140, IC-415159, IC-415163 and IC-421815 eight were pubescent (Table 2). Leaf margin: Two categories of leaf margin (smooth and serrated) were observed. Among the genotypes, 73 were found to have smooth margin and 11 were serrated margin (Table 2). Leaf type: Two classes of leaf type namely narrow and broad were observed. Narrow leaf types were found to be higher (72) when compared to broad leaf type (12) (Table 2). Flower color: Among the genotypes, two categories namely purple and white flowers were observed. Purple color was found in majority of the genotypes (74). Ten genotypes were found with white flower color (Table 2). Seed color: Maximum number of twenty two genotypes possessed grey green group and grey brown group each; however, in grey group nineteen genotypes were recorded regarding brown group had twelve genotypes. Among them only ten genotypes were recorded in grayed yellow group (Table 2 and Table 3 ). Among the qualitative traits, the trait seed color showed a higher class of variation (five groups) and all other traits showed only two groups. Grey brown group in seed color, white color in flower color, glabrous in leaf surface, branched stem in stem type, serrated margin in leaf margin, bushy in growth habit and narrow type in leaf type were observed as dominant spectrum among other classes of qualitative traits. Leaf type and leaf surface together are easily distinguished the vegetable genotypes from gum genotypes. The distinct feature broad and glabrous leaf surface is helpful in identifying as a vegetable type. However, the trait narrow leaf type with pubescence is associated with gum genotypes. Kumar et al. (2013) employed the above traits for varietal characterization in guar. Such a unique morphological trait can be directly employed in seed production plots to rougue out the off types (vegetable type) from the gum genotypes in field level even at initial stage of crop growth. Twelve genotypes were identified as non branching types (single stem). Sivakumar (2002) and Kumar et al. (2013) also identified two genotypes namely RGC 197 and FS 277 with a single stem type. Single stem genotypes are very much preferred as they bear more number of pods per cluster and also used as a preferred intercrop in cotton fields or a shade crop in ginger fields. Such a stem type serves as a useful marker in seed production plots. Among the predominant white colour flowers, eleven genotypes had pink flower colour. Kumar et al. (2013) distinguished the genotypes based on pink flower colour. Flower colour aids in maintenance of purity at flowering stage which reduces contamination in seed production. Twelve genotypes showed brown seed with distinct grade of N 200 B which was distinctly unique and differed from the predominant grey group seeds. High morphological variability was observed in guar cultivars and respect to pubescence of the plant, pattern of branching, bearing habit, shape, size and texture of the pods, seed size and color, and also quantity of gum in the seeds and also these traits were widely employed for characterization of cluster bean germplasm (Sultan et al., 2012; Morris, 2010 and Fletcher and Murphy, 1998).

\section{CONCLUSION}

Cluster bean which is a self-pollinated crop though there is a potential for obtaining hybrid vigor by implementing hybridization programme with both qualitative and quantitative traits of different genotypes of distinct group to obtain superior and promising genotypes from the segregating generation therefore this study may gives ingredient to the selection of superior genotypes among the germplasm.

\section{ACKNOWLEDGMENT}

The work presented in this paper is a part of the Ph.D. thesis carried out by Dr. B Niranajana Kumara at Department of Genetics and Plant Breeding, College of Agriculture, University of Agricultural and Horticultural Science, Shivamogga, Karnataka, India. The financial sup-port provided by Department of Science and Technology, New Delhi, by awarding INSPIRE fellowship is gratefully acknowledged.

\section{REFERENCES}

[1] R. Fletcher and Murphy H., The new rural industries: a handbook for farmers and investors. Canberra, Australia, 1998, pp.343-346.

[2] T. Hymowitz and R. S. Matlock, 1963. Guar in the United States, Oklahoma Agricultural Experiment Station Technical Bulletin. 611:134.

[3] S. Kumar and U. N. Joshi, 2013. Characterization of released and elite genotypes of guar (Cyamopsis tetragonoloba (L.)Taub.) From India proves unrelated to geographical origin. Genetic Resources and Crop Evolution. pp. 1573-5109. https://doi.org/10.1007/s10722-013-9970-7

[4] P. C. Mahalanobis, 1936. On the generalized distance in statistics. Proceedings National Institute of Science, India. 2: 49-55.

[5] J. B. Morris, 2010. Morphological and reproductive characterization of guar (Cyamopsis tetragonoloba) genetic resources regenerated in Georgia, USA. Genetic Resources and Crop Evolution 57: 985-993. https://doi.org/10.1007/s10722-010-9538-8

[6] R. Pathak and M. Singh, 2009. Genetic divergence in clus-terbean (Cyamopsis tetragonoloba (L.) Taub.) for seed yield and gum content under rainfed conditions, Indian J. Agricultural Science. 79(7): 559561.

[7] J. W. Purseglove, 1981. Leguminosae. In: Tropical Crops: Dicotyledons, Longman Group Ltd., Essex, U.K. pp.250-254.

[8] Sivakumar. 2002. Characterization of cluster bean cultivars using laboratory techniques and filed parameters. M.Sc. Thesis, Haryana Agricultural University, Hisar.

[9] M. Sultan and M. A. Rabbani, 2012. Phenotypic divergence in guar (Cyamopsis tetragonoloba L.) landrace genotypes of Pakistan. Pakistan J. Botany. 4(4): 203-210. 
TABLE 1: Description of quality parameters

\begin{tabular}{|c|c|c|c|c|c|c|c|c|}
\hline Score & Traits & Stem type & $\begin{array}{c}\begin{array}{c}\text { Growth } \\
\text { habit }\end{array} \\
\end{array}$ & Leaf surface & Leaf margin & Leaf type & $\begin{array}{c}\text { Flower } \\
\text { color }\end{array}$ & Seed color \\
\hline 1 & \multirow{5}{*}{ Description } & Branched & Bushy & Glabrous & Serrated & Narrow & Purple & Grey \\
\hline 2 & & Non branched & Erect & Pubescent & Smooth & Broad & White & Grey brown \\
\hline 3 & & & & & & & & Grey green \\
\hline 4 & & & & & & & & Grey yellow \\
\hline 5 & & & & & & & & Brown group \\
\hline
\end{tabular}

TABLE 2. Qualitative traits score based on descriptor

\begin{tabular}{|c|c|c|c|c|c|c|c|c|}
\hline Si. No. & Genotypes & Stem type & Growth habit & Leaf surface & Leaf margin & Leaf type & $\begin{array}{c}\text { Flower } \\
\text { color }\end{array}$ & $\begin{array}{l}\text { Seed } \\
\text { color }\end{array}$ \\
\hline 1 & IC-421816 & 2 & 1 & 1 & 1 & 2 & 1 & 1 \\
\hline 2 & IC-421817 & 1 & 1 & 1 & 1 & 1 & 1 & 2 \\
\hline 3 & IC-311392 & 2 & 1 & 1 & 2 & 1 & 1 & 3 \\
\hline 4 & IC-311393 & 2 & 2 & 1 & 1 & 1 & 2 & 1 \\
\hline 5 & IC-311403 & 2 & 1 & 1 & 1 & 1 & 1 & 2 \\
\hline 6 & IC-311417 & 2 & 1 & 1 & 1 & 2 & 1 & 4 \\
\hline 7 & IC-311431 & 2 & 1 & 1 & 1 & 1 & 1 & 5 \\
\hline 8 & IC-311432 & 2 & 1 & 1 & 2 & 1 & 1 & 4 \\
\hline 9 & IC-311440 & 2 & 1 & 2 & 1 & 1 & 1 & 5 \\
\hline 10 & IC-311444 & 2 & 1 & 1 & 1 & 1 & 2 & 2 \\
\hline 11 & IC-311449 & 2 & 1 & 1 & 1 & 1 & 1 & 3 \\
\hline 12 & IC-323992 & 2 & 1 & 2 & 1 & 1 & 1 & 4 \\
\hline 13 & IC-324020 & 2 & 1 & 1 & 1 & 1 & 1 & 5 \\
\hline 14 & IC-324023 & 2 & 2 & 1 & 2 & 2 & 1 & 1 \\
\hline 15 & IC-325743 & 2 & 1 & 1 & 1 & 1 & 1 & 2 \\
\hline 16 & IC-325800 & 2 & 1 & 1 & 1 & 1 & 1 & 3 \\
\hline 17 & IC-325806 & 2 & 1 & 2 & 1 & 1 & 1 & 2 \\
\hline 18 & IC-325811 & 2 & 1 & 1 & 1 & 1 & 1 & 1 \\
\hline 19 & IC-325819 & 2 & 1 & 1 & 1 & 1 & 1 & 2 \\
\hline 20 & IC-325821 & 2 & 1 & 1 & 1 & 1 & 1 & 3 \\
\hline 21 & IC-325832 & 2 & 2 & 1 & 1 & 2 & 2 & 4 \\
\hline 22 & IC-325846 & 2 & 1 & 1 & 1 & 1 & 1 & 2 \\
\hline 23 & IC-329030 & 2 & 1 & 1 & 1 & 1 & 1 & 1 \\
\hline 24 & IC-329033 & 2 & 1 & 1 & 1 & 1 & 1 & 3 \\
\hline 25 & IC-329036 & 2 & 1 & 1 & 1 & 2 & 1 & 3 \\
\hline 26 & IC-329062 & 2 & 1 & 2 & 1 & 1 & 1 & 1 \\
\hline 27 & IC-369838 & 2 & 1 & 1 & 1 & 1 & 1 & 2 \\
\hline 28 & IC-370478 & 1 & 2 & 1 & 2 & 1 & 1 & 3 \\
\hline 29 & IC-370490 & 2 & 1 & 1 & 1 & 1 & 1 & 3 \\
\hline 30 & IC-370502 & 2 & 1 & 1 & 1 & 1 & 1 & 3 \\
\hline 31 & IC-370509 & 2 & 1 & 1 & 1 & 1 & 2 & 1 \\
\hline 32 & IC-370516 & 2 & 1 & 2 & 1 & 1 & 1 & 2 \\
\hline 33 & IC-370563 & 2 & 1 & 1 & 1 & 1 & 1 & 3 \\
\hline 34 & IC-373427 & 2 & 1 & 1 & 2 & 1 & 1 & 2 \\
\hline
\end{tabular}




\begin{tabular}{|c|c|c|c|c|c|c|c|c|}
\hline Si. No. & Genotypes & Stem type & Growth habit & Leaf surface & Leaf margin & Leaf type & $\begin{array}{c}\text { Flower } \\
\text { color }\end{array}$ & $\begin{array}{l}\text { Seed } \\
\text { color }\end{array}$ \\
\hline 35 & IC-373438 & 2 & 1 & 1 & 1 & 2 & 1 & 1 \\
\hline 36 & IC-373480 & 2 & 1 & 1 & 1 & 1 & 1 & 3 \\
\hline 37 & IC-373497 & 2 & 1 & 1 & 1 & 1 & 1 & 2 \\
\hline 38 & IC-373557 & 2 & 1 & 2 & 2 & 1 & 1 & 1 \\
\hline 39 & IC-402294 & 2 & 1 & 1 & 1 & 1 & 1 & 3 \\
\hline 40 & IC-402295 & 2 & 1 & 1 & 1 & 2 & 1 & 4 \\
\hline 41 & IC-402296 & 1 & 2 & 1 & 1 & 1 & 1 & 5 \\
\hline 42 & IC-402298 & 2 & 1 & 1 & 1 & 1 & 1 & 1 \\
\hline 43 & IC-402299 & 2 & 1 & 1 & 1 & 1 & 1 & 2 \\
\hline 44 & IC-402301 & 2 & 1 & 1 & 1 & 1 & 2 & 3 \\
\hline 45 & IC-402302 & 2 & 1 & 1 & 1 & 1 & 1 & 2 \\
\hline 46 & IC-402303 & 2 & 1 & 1 & 1 & 1 & 1 & 2 \\
\hline 47 & IC-402304 & 2 & 1 & 1 & 1 & 1 & 1 & 2 \\
\hline 48 & IC-415102 & 2 & 1 & 1 & 1 & 1 & 1 & 2 \\
\hline 49 & IC-415106 & 1 & 1 & 2 & 1 & 1 & 1 & 2 \\
\hline 50 & IC-415108 & 2 & 1 & 1 & 2 & 1 & 1 & 2 \\
\hline 51 & IC-415110 & 2 & 1 & 1 & 1 & 2 & 1 & 3 \\
\hline 52 & IC-415115 & 2 & 1 & 1 & 1 & 1 & 1 & 3 \\
\hline 53 & IC-415123 & 1 & 1 & 1 & 1 & 1 & 1 & 3 \\
\hline 54 & IC-415125 & 2 & 1 & 1 & 1 & 1 & 1 & 3 \\
\hline 55 & IC-415128 & 2 & 2 & 1 & 1 & 1 & 2 & 3 \\
\hline 56 & IC-415131 & 2 & 1 & 1 & 1 & 1 & 1 & 3 \\
\hline 57 & IC-415135 & 2 & 1 & 1 & 1 & 1 & 1 & 2 \\
\hline 58 & IC-415137 & 2 & 1 & 1 & 1 & 1 & 1 & 2 \\
\hline 59 & IC-415138 & 2 & 1 & 1 & 1 & 1 & 1 & 3 \\
\hline 60 & IC-415140 & 2 & 1 & 2 & 2 & 1 & 1 & 1 \\
\hline 61 & IC-415145 & 1 & 1 & 1 & 1 & 1 & 1 & 1 \\
\hline 62 & IC-415146 & 1 & 1 & 1 & 1 & 1 & 1 & 1 \\
\hline 63 & IC-415148 & 2 & 1 & 1 & 1 & 2 & 2 & 4 \\
\hline 64 & IC-415151 & 2 & 1 & 1 & 1 & 1 & 1 & 4 \\
\hline 65 & IC-415153 & 2 & 1 & 1 & 1 & 1 & 1 & 5 \\
\hline 66 & IC-415154 & 2 & 2 & 1 & 1 & 1 & 1 & 5 \\
\hline 67 & IC-415157 & 2 & 1 & 1 & 1 & 1 & 1 & 5 \\
\hline 68 & IC-415158 & 2 & 1 & 1 & 1 & 1 & 1 & 5 \\
\hline 69 & IC-415159 & 2 & 1 & 1 & 2 & 2 & 1 & 5 \\
\hline 70 & IC-415160 & 2 & 1 & 1 & 1 & 1 & 2 & 3 \\
\hline 71 & IC-415161 & 1 & 1 & 1 & 1 & 1 & 1 & 4 \\
\hline 72 & IC-415163 & 2 & 1 & 2 & 2 & 1 & 1 & 4 \\
\hline 73 & IC-415166 & 2 & 1 & 1 & 1 & 1 & 1 & 4 \\
\hline 74 & IC-415168 & 2 & 1 & 1 & 1 & 1 & 1 & 2 \\
\hline 75 & IC- 420320 & 2 & 1 & 1 & 1 & 2 & 1 & 3 \\
\hline 76 & IC-420332 & 2 & 1 & 1 & 1 & 1 & 2 & 1 \\
\hline 77 & IC-420373 & 1 & 2 & 1 & 1 & 1 & 1 & 5 \\
\hline
\end{tabular}


Int'I Journal of Advances in Agricultural \& Environmental Engg. (IJAAEE) Vol. 4, Issue 1 (2017) ISSN 2349-1523 EISSN 2349-1531

\begin{tabular}{|c|c|c|c|c|c|c|c|c|}
\hline Si. No. & Genotypes & Stem type & Growth habit & Leaf surface & Leaf margin & Leaf type & $\begin{array}{c}\text { Flower } \\
\text { color }\end{array}$ & $\begin{array}{c}\text { Seed } \\
\text { color }\end{array}$ \\
\hline 78 & IC-421242 & 2 & 1 & 1 & 1 & 1 & 1 \\
\hline 79 & IC-421798 & 2 & 1 & 1 & 1 & 1 & 1 \\
\hline 80 & IC-421809 & 2 & 1 & 1 & 2 & 1 & 1 \\
\hline 81 & IC-421812 & 2 & 1 & 1 & 1 & 1 & 1 \\
\hline 82 & IC-421815 & 2 & 1 & 2 & 1 & 1 & 2 \\
\hline 83 & IC-421834 & 2 & 1 & 1 & 1 & 1 & 1 \\
\hline 84 & IC-421835 & 2 & 1 & 1 & 1 & 2 & 1 \\
\hline 85 & RGC1003 & 2 & 1 & 1 & 1 & 1 & 1 \\
\hline
\end{tabular}

TABLE 3. Distribution of phenotypic classes among qualitative traits

\begin{tabular}{|c|c|c|c|c|}
\hline Descriptor & Score & Category & Number of genotypes & Frequency (\%) \\
\hline \multirow{5}{*}{ Seed colour } & 1 & Grey Group & 19 & 22.35 \\
\hline & 2 & Grey- Brown Group & 22 & 25.88 \\
\hline & 3 & Greyed- Green Group & 22 & 25.88 \\
\hline & 4 & Greyed- Yellow Group & 10 & 11.76 \\
\hline & 5 & Brown Group & 12 & 14.11 \\
\hline \multirow{2}{*}{ Flower colour } & 1 & White & 74 & 87.05 \\
\hline & 2 & Purple & 11 & 12.94 \\
\hline \multirow{2}{*}{ Leaf surface } & $\frac{2}{1}$ & Glabrous & 72 & 84.70 \\
\hline & 2 & Pubescence & 12 & 14.11 \\
\hline \multirow{2}{*}{ Stem type } & 1 & Branched & 73 & 85.88 \\
\hline & 2 & Unbranched & 12 & 14.11 \\
\hline \multirow{2}{*}{ Leaf margin } & 1 & Serrated & 74 & 87.05 \\
\hline & 2 & Smooth & 11 & 12.95 \\
\hline \multirow{2}{*}{ Growth habit } & $\frac{2}{1}$ & Bushy & 77 & 90.58 \\
\hline & 3 & Erect & 8 & 9.41 \\
\hline \multirow{2}{*}{ Leaf type } & 1 & Narrow & 70 & 82.35 \\
\hline & 3 & Broad & 15 & 17.64 \\
\hline
\end{tabular}

